\title{
The world experience analysis of ecological systems in construction on the high-rise air purification and filtration towers example
}

\author{
Alisa Nesterova* $^{*}$ and Yulia Danilovich \\ Moscow State University of Civil Engineering (MGSU) National Research University, 129337, \\ Moscow, Russia
}

\begin{abstract}
The article discusses the world experience in the construction and operation of high-rise towers with the air purification and filtrationfunction. The main advantages of this technology are considered, the pros and cons are given, as well as the examples of existing buildings and structures. It is concluded that modern urban planning focuses on environmental friendliness and energy efficiency of buildings, therefore, air purification and filtration technology is extremely relevant.
\end{abstract}

\section{Introduction}

The problem of an unfavorable ecological situation is quite acute all over the world. At the moment, about 3.5 billion people on Earth live in cities. It is known that buildings around the world use $40 \%$ of all primary energy consumed, $67 \%$ of electricity, $40 \%$ of raw materials and $14 \%$ of drinking water supplies, and also produce about $35 \%$ of carbon dioxide emissions and almost half of all municipal solid waste. The presence of these factors requires a change in attitude towards housing construction. In this regard, air purification and filtration towers, as well as high-rise buildings with introduced air purification structures began to appear in large cities.

Energy consumption of modern high-rise buildings is a pressing issue. Recently, society has significantly changed its attitude to the environment and energy consumption, which required the construction technologies development and the construction of energy-efficient and energy-sustainable, environmentally sound, environmentally friendly buildings.

At present, unfavorable ecology is the most important problem that requires early solution. Almost all over the world, a significant amount of time is currently allocated for the development of environmental and energy-saving technologies aimed at reducing the harmful effect on the environment and economical use of energy resources. The solution of environmental problems is paid close attention to at the highest level: "In 2021, the costs of the national project in the field of ecology will be increased by almost half, in general, in three years, 1 trillion rubles will be allocated from the federal budget for environmental protection for the first time," announced V.V. Putin, noting that the funds will be used to reduce air pollution.

\footnotetext{
* Corresponding author: Lisa.858@yandex.ru
} 


\section{Main part}

Smog in the world's major metropolitan areas is also a serious problem. Polluted air in multi-million-dollar centers negatively affects the entire climate on the planet. According to WHO city smog kills three times as many people as car accidents. The problem of smog is especially acute in China. In this regard, separate air purification towers began to appear there, as well as the structures built into high-rise buildings. Also, the buildings and structures designed for air purification exist in Holland, Singapore and Germany.

- The world's largest urban air purifier is built in the Chinese city of Xian in Shaanxi province (Figure 1). The tower was tested by the researchers from the Institute of Earth Environment of the Chinese Academy of Sciences. In many cities in northern China, including Xian, the atmosphere is deteriorated in winter. This is due to the heating of homes with coal-fired power plants.
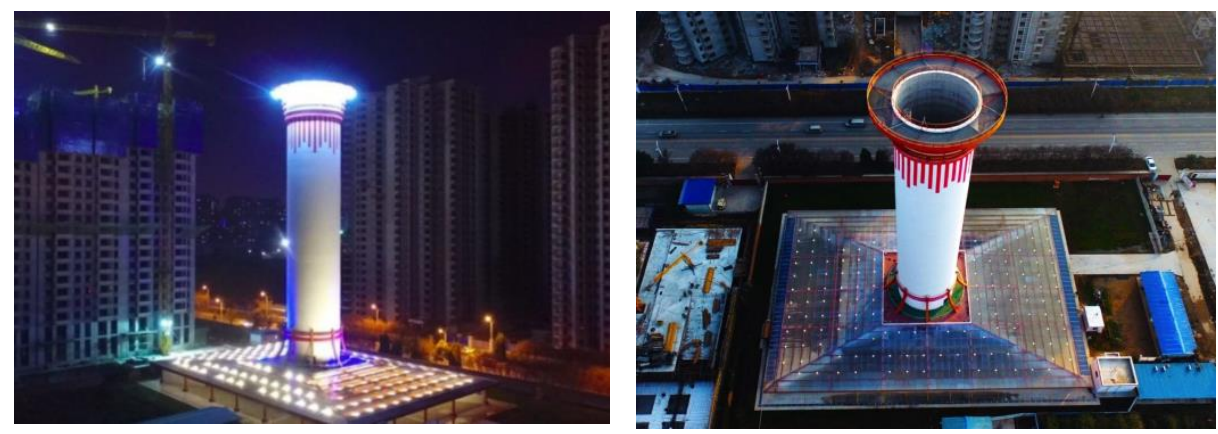

Fig. 1. Xian smog tower in Xian (China)

The system works with greenhouses at the base of the tower, covering an area equal to $1 / 2$ of a football field. The polluted air is sucked into the greenhouses and heated by solar energy. Then hot air rises up the tower and is cleaned with several layers of filters. The system also functions in cold weather - coatings in greenhouses providing the glass with an ability to absorb the Sun rays. Even the international environmental organization Greenpeace admits that China is starting to win the battle against air pollution in major cities. Since its launch, the tower has produced over 10 million cubic meters of clean air per day, and pollution levels across the 10 square kilometers site have been noticeably decreased in recent months. When smog was particularly strong, the tower reduced it to moderate (Figure 2).

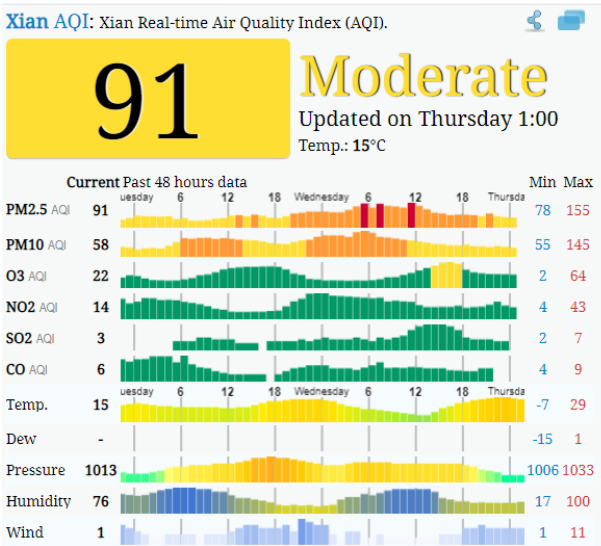

Fig. 2. Xian Air Quality Index (AQI) 
- On June 29, 2012, an unusual garden was opened in Singapore. On a huge parkland, engineers from the British architectural firm Grant Associates have built unusual structures imitating giant trees. "Super tree" (Figure 3), as the designers called them. These trees collect and store energy from solar panels installed on them, which is then used to illuminate trees and all buildings on this part of the embankment, as well as collect rainwater for fountains and watering plants in the garden. In addition, some of the Super trees are equipped with conservatories and serve as intake and exhaust towers that help reduce ambient temperatures by absorbing and dissipating heat. Experts estimate that towers save about 30 percent energy compared to traditional cooling methods.
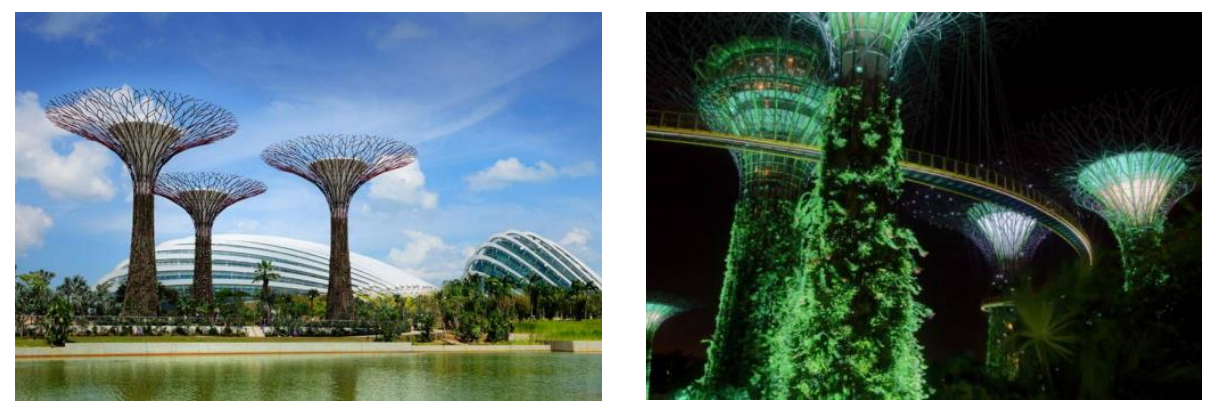

Fig. 3. Huge artificial trees in Gardens by the Bay, Singapore.

- Striving for the construction of energy efficient buildings with zero energy consumption and a closed life support cycle is the main trend in the design of high-rise buildings and in modern urban planning in general. The 310-meter, 71-story Pearl River Tower in Guangzhou, China (Figure 4) is designed as a zero-energy building, meaning it does not consume electricity from the external grid.
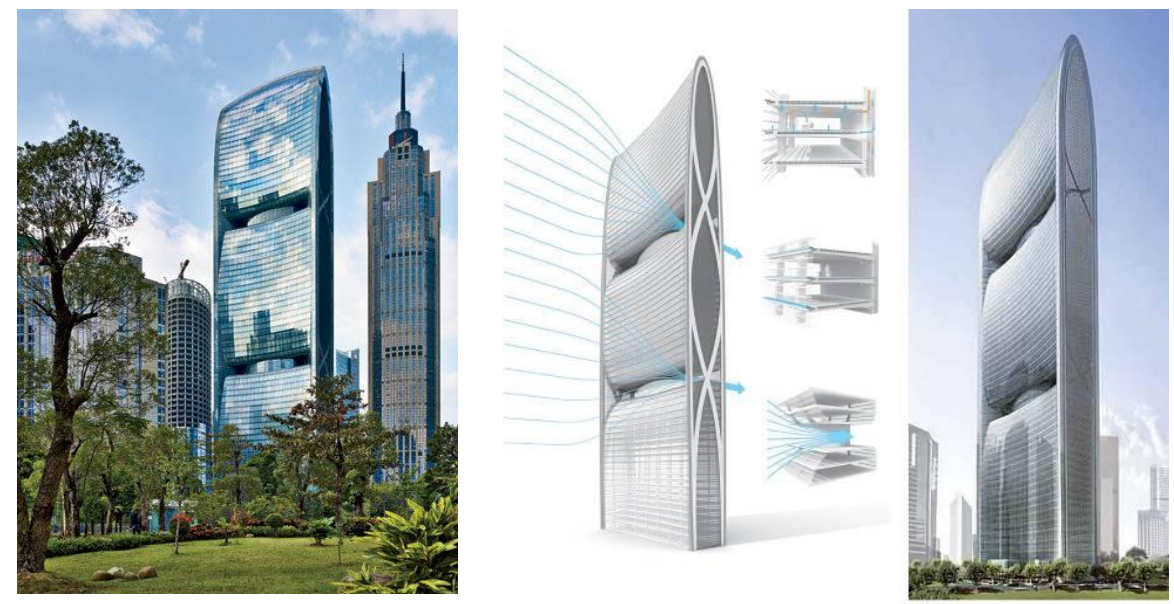

Fig. 4. The Pearl River Tower Project, Guangzhou, China

A technical innovation in the Pearl River Tower is the use of wind turbines. The facade of the skyscraper in the form of a giant vertical wave smoothly curves in front of each channel with wind turbines. Four wind turbines with a diameter of $6 \mathrm{~m}$ are built from the outside into openings in the building technical floors enclosing structures - two units in each of the three technical floors (Figure 5). The air flows into the resulting giant gap will 
be directed with greater force, contributing to the increase in the huge turbine blades rotation and potentiating the energy megawatts generation. In addition to generating electricity, the incoming air is cleaned thanks to the air filters installed on the technical floors.
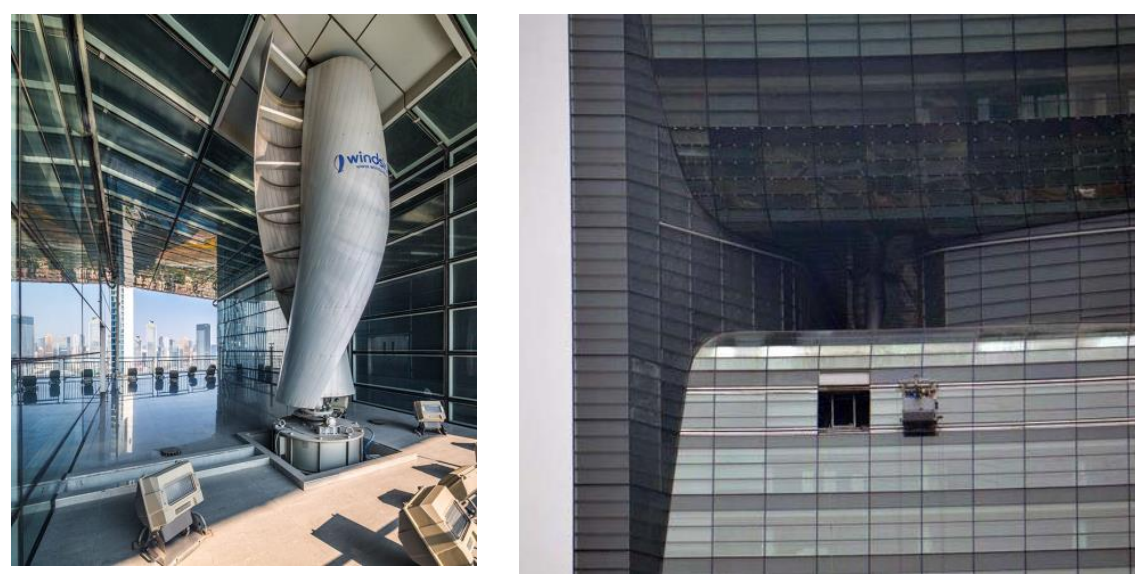

Fig. 5. Close-up of one of the building's indoor wind turbines

- Smog Free Tower - it is a tower with air purifier function. In recent years, Beijing residents have witnessed severe air pollution. According to the Beijing Environmental Protection Bureau, the capital had 186 days with good air quality last year, accounting for 51 percent of the total. The height of the tower is seven meters, and from the outside it looks like a steel hexagonal sculpture (Figure 6).
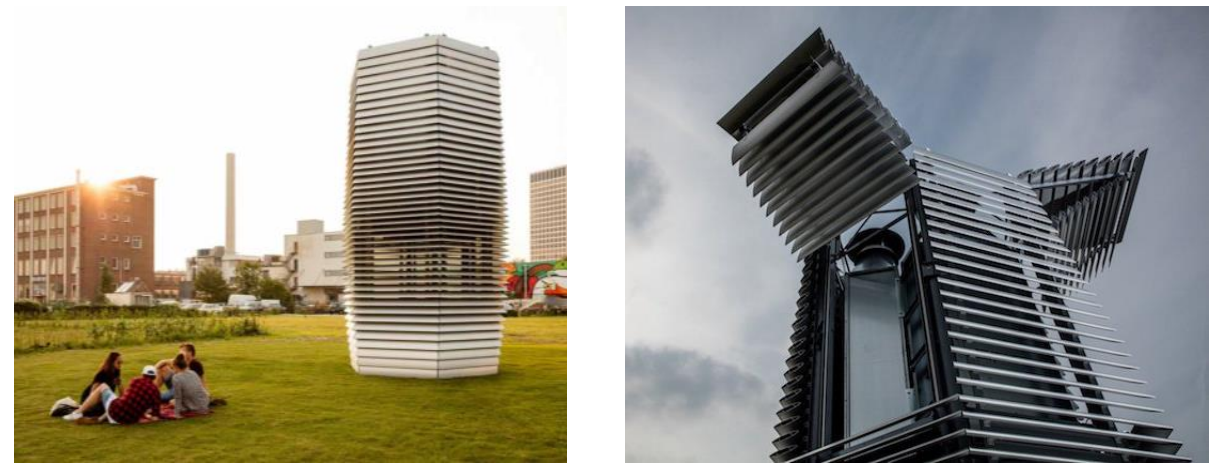

Fig. 6. Smog Free Tower, Beijing, China)

The Smog Free Tower removes harmful particles of smog and other types of contaminants in the air. The plant has enough capacity to purify 30 thousand cubic meters of air per hour.

Smog Free Tower works on the principle of an "electrostatic vacuum cleaner". The space in the upper part of the tower is saturated with positively charged ions, which "precipitate" the particles of ultrafine suspension, a carcinogenic and dangerous component of smog. Further, following in the flow of air forced by the fan, they come into contact with the filter in the form of a negatively charged surface. The results confirm that the unit captures and removes up to $70 \%$ of ingested PM10 and up to 50\% of ingested PM2.5 (Figure 7). 


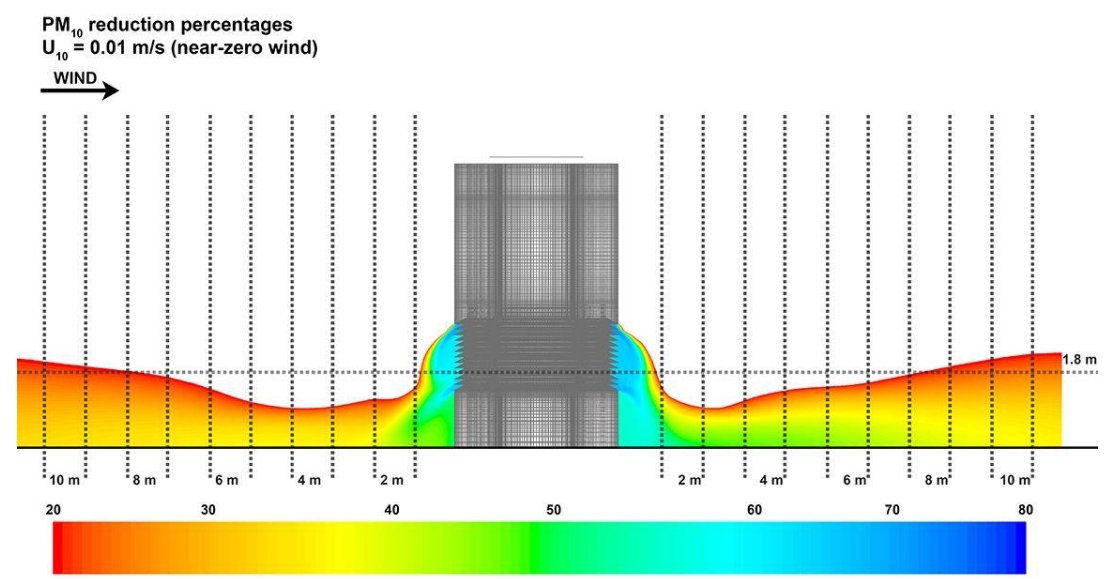

Fig. 7. Percentage reduction of PM10 concentration with SFT in near-zero wind conditions up to 10 $\mathrm{m}$ from the tower (Photo: Eindhoven University of Technology)

Despite the uniqueness of the architectural and engineering solutions of buildings and structures with the function of cleaning and filtering air, as well as other buildings belonging to this category, our analysis made it possible to highlight the main features characteristic of such buildings:

- using the energy potential of nature in the existing climate to supply energy to the building;

- maximum use of the premises'natural ventilation;

- maximum use of natural lighting in rooms;

- intelligent engineering equipment.

\section{Air purification tower concept in Moscow}

Based on the world experience in the construction of air purification and filtration towers, we propose to develop a concept for an air purification tower in Moscow. Analysis of various buildings and structures allows us to suggest the best solution. We propose to consider the concept of a high-rise tower with several technical floors, on which the equipment for cleaning and filtering the ambient air will be located. High-rise buildings that will undoubtedly enrich the silhouette of our capitalis being actively built inMoscow. The clusters of tall buildings, easily visible from major highways, will create vibrant and desirable landmarks in the city. Many of the modern skyscrapers in the world have become the new symbols of modern urban civilization, which will also have a beneficial effect on the city appearance. The conceptdevelopment of such a tower in Russia gives an opportunity to assume a tendency in the ecological construction development in our country. But in addition to developing the architectural appearance of the building, it is also necessary to consider the advantages and disadvantages of its construction on the territory of Moscow.

\section{Advantages and disadvantages}

The main advantages of using this type of technology are:

1. Environmental function. The most obvious and obvious advantage is air purification and filtration. In modern cities, the problem of air purity is becoming more acute, and even more so, this has not spared Moscow. There are factories in the metropolis that 
inevitably emit harmful substances into the atmosphere, as well as a huge daily flow of cars that also generate toxic gases.

2. The introduction of new modern technologies in construction in Russia. Having used the concept of a building with an air purification function for the first time, this technology will be developed in the future and become more accessible in our country. Many Russian cities have extremely unfavorable environmental conditions and they also require similar air purification towers.

3. Energy efficiency. There are buildings in the world that not only purify the air, but also receive energy from purification, which then goes to the self-sufficiency of the building. This technology would make it possible to build more energy efficient buildings in Russia.

But in addition to the advantages of technology, it is also worth considering the disadvantages that lie in:

1. Cost. Undoubtedly, such a building with an air purification function will cost an order of magnitude more than an ordinary skyscraper with similar parameters. In addition to the rise in development costs, due to the lack of examples in the Russian market, the equipment that will need to be installed to clean and filter the ambient air is also expensive.

2. Lack of concept in Russia. This means that many decisions during construction will have to be made based on foreign experience, which is not always suitable for the Russian climate. In addition, information about equipment suitable for our purposes is not available in open sources. Therefore, it may be necessary for construction to develop the concept of equipment for cleaning and filtering air, suitable for high-rise towers in the city.

3. Architectural appearance. In addition to the environmental friendliness of modern construction, it is necessary to think about the organic fit of air purification products into the modern cityimage. When creating such an air purification tower, it is worth relying on the construction area and choosing the place that is most polluted. In Moscow, the air is most polluted in the city center, but the ensemble of the old fund can be disturbed by the modern and decorative view of the high-rise tower, in this regard, it is worth considering the problem of inscribing modern architectural forms in the cities of Russia.

\section{Conclusion}

From all the above-presented information, we can conclude that the construction of highrise towers for air purification and filtration based on foreign experience will become a new round of technology in Russia, but in addition it will require a lot of money and resources. In addition to existing air purification and filtration facilities, it is also worth considering other technologies that can be introduced into construction to be more environmentally friendly. With the further development of this construction technology, the environmental situation in many cities can significantly improve, which will positively affect the quality of life.

\section{References}

1. V.I. Telichenko, A.A. Benuzh, Industrial and civil construction 10 (2014). URL: pgs1923.ru/russian/rindex.htm (access date: 25.03.2019).

2. M.M. Brodach, Engineering equipment of high-rise buildings (Avok Press, Moscow, 2007). 
3. G. He et.al. Environ. Dev. 3 July (2012).

4. Documentaries. Superstructures: Eco-skyscraper in China.

5. O.V. Bliznyuk, Construction Economics 2 (14) (2012).

6. A.V. Ryabov, Architecture and modern information technologies 2 (11) (2010).

7. O.V. Stakheev, E.E. Bravova, Regional architectural and art schools 1 (2011). 